\title{
Connection Between the Number of Complaints About Welding Suppliers and End Product Quality: The Case of Customized Welding Production
}

\author{
Jenni Toivanen, Harri Eskelinen, Paul Kah, Jukka Martikainen \\ Mechanical Engineering, Lappeenranta University of Technology, Lappeenranta, Finland
}

Email address:

jenni.toivanen@lut.fi (J. Toivanen)

\section{To cite this article:}

Jenni Toivanen, Harri Eskelinen, Paul Kah, Jukka Martikainen. Connection Between the Number of Complaints About Welding Suppliers and End Product Quality: The Case of Customized Welding Production. International Journal of Mechanical Engineering and Applications. Vol. 4, No. 2, 2016, pp. 43-49. doi: 10.11648/j.ijmea.20160402.12

\begin{abstract}
Although undesirable, manufacturing defects leading to complaints are almost inevitable in the production of manufactured products, and consideration of manufacturing quality is therefore an essential aspect of management of supply chains with multiple suppliers. This study evaluates the relationship between complaints about the end product and welding production in a multiple supplier chain. In the studied case, it was noticed that there is potential for improved welding production management by suppliers to increase profitability by decreasing the number of welding defects that cause complaints. This study shows one approach to analysis of the relation between complaints in the supply chain and their effect on the end product.
\end{abstract}

Keywords: Welding Production, Welding Suppliers, Complaints, Welding Quality, Productivity Improvement, Empirical Study

\section{Introduction}

Supply chain quality and manufacturing have been the subject of active research interest and the topics have been examined from many perspectives, for instance, from the viewpoint of management [1, 2, 3], partnership [4], products $[5,6]$ and costs [7, 8]. From the point of view of manufacturing quality, the quality of supplier relationships [9] is an important aspect in supply chain management. Quality management is usually separated into segments such as internal actions of operations managers within organisations and external actions with purchasing and logistic functions [1].

Researchers have studied issues related to the supply chain such as production with defects [10], customer complaints about service $[11,12]$ and data modelling for organizational learning from complaints [13]. Researchers' interest has also been drawn to complaints related to latent defects with no discovered reason [14], false failure returns [15] and the impact of supplier production rate on defects and production costs [16]. When studying human factors, Mateo et al. [17], using production data, found that there is no significant relation between complaints and absenteeism, and Gajdzik and Sitko [18] found a relation between complaints and human errors in steel sheets manufacturing.

Generally, existing research on complaint management and complaints in production are based on modelling [19] and interviews or questionnaires [3, 20]. Furthermore, the studies tend to be general in nature, giving generic recommendations. Despite the importance of general results, which give valuable information about issues of concern and suggestions for management of relevant aspects of complaints handling, there is a need for more substantive data-based results and more profound observation of complaints and their effect on production and costs. Of particular interest is mirroring complaints data to complete product data as a means of discovering prospective processes to increase profitability.

This paper evaluates the effect of complaints on the end product in a welding production supply chain with multiple suppliers. The approach provides new insights into the effect of complaints about a specific manufactured product and manufacturing process and indicates actions that may lead to increased profitability. The study considers the following research questions: firstly, how the characteristics of 
complaints about welding reflect the quality and costs of the end product; and secondly, whether there is potential to influence the quality and profitability of manufacturing of the end product by improved control of the welding supply chain. Results of the studied case show clearly the role of welding production in end product quality in multisectoral manufacturing and thus its importance in manufacturing quality. The paper consists of two parts: a theoretical part considering the theoretical background and an empirical research part utilizing complaints data of the case focal company in the welding supplier chain.

The novelty value of this research is based on the new viewpoint of complaint analysis, which is supported by statistical data and reliability calculations to which data is collected from both the PDM system and complaint system. The results of this analysis are verified with more than 14 000 real case examples.

\section{Complaints Run Out from Profitability}

Quality of manufacturing is important thus complex with multiple manufacturer in supply chain. Coordination of supply chain [21], strategic supply chain management [22] and thus, strategic supplier selection is acting more significant role in manufacturing [23]. In welding manufacturing the one typical structure of manufacturing is structure where the focal company dominates the manufacturing with multiple suppliers [24]. This kind of structure leads to especially dyadic contacts but the increase of cooperation between network members also enables multitiered relationships and augmented manufacturing. However, its complexity introduces multiple functions and linkages that can have an effect on defect incidence and end product quality [25].

The focal manufacturer in such a network defines the product quality and price [26], which encompass, among other costs, the costs of development and manufacturing. Inadmissible parts in production inevitably cause disturbances in the manufacturing chain, and defects and failures generate unnecessary expense in the form of rework and waste. The costs arising from defects consist of internal failure costs from scrap, rework and delay, and external failure costs from repairs, warranty claims and lost custom [27]. These additional costs reduce the profitability of the end product and therefore complaints do not promote profitable outcomes. Complaints leading to additional waste also complicate efforts to reduce the negative environmental impacts of manufacturing [28].

However, defects leading to complaints are almost inevitable in production with multiple member manufacturing chains and the effect of inadmissible results can magnify across the multiple actors involved. Complaints can originate for many different reasons, for example, product defect, damage during transportation, or even as a result of misunderstandings. It should be noted that even false failures or returns for no reason are detrimental to suppliers [15], and they cause unnecessary expenses for both the supplier and the focal company. Complaint behaviour and complaint management are essential to ensure effective relationship in business [20] and effective relationships enable essential in profitable manufacturing. Competitive advantage in manufacturing need continuous improvement of product quality [29] and thus cost of quality seems to have more strategic and economic importance compared to previous time [7].

Quality design plays an important role in business decisions concerning quality level and actions, and, thus, the costs of quality. In a dynamic manufacturing chain, farsighted (i.e., economically long-term focused) quality behaviour results in a more price-sensitive demand than a myopic (i.e., economically short-term focused) approach. The myopic approach provides consumers with a higher quality-price ratio and more quality sensitive but less pricesensitive market [26]. The balance between quality and product costs is difficult to define when coordinating a complex manufacturing chain. Product quality data can be valuable for managing suppliers and product quality. Based on information from monitoring the quantity and type of complaints generated, the focal company can take remedial and optimization actions to gain improved profitability and enhanced production quality at the network level of the dynamic manufacturing chain. Quality data thus form an important basis for decision making regarding activities related to quality control, management and improvement [29]. Effective utilization of complaints data can assist the focal company in control of quality costs.

\section{Research Methods}

In this study, numerical data of complaints relating to welding suppliers and two welded case products were gathered and analysed. The case products, which are two different mobile machines, are end products with a large number of different parts that are sourced from many suppliers. Analysis of the complaints data focused on items manufactured by welding suppliers and their effect on quality and profitability in the welding network.

\subsection{Data Collection}

Case end products, Machine A and Machine B, are mobile machines designed for work in demanding environments, and the machines consist of multiple welded parts and structures with multiple items. The products consist of 3891 different items and the total number of parts is 14907 . Data about the parts used in this study are from the company's PDM (Product Data Management) system and data about complaints are from the company's complaints system. The gathered data were tabulated and percentage portions were calculated and scaled to find links between complaints and potential for increased production profitability. Identification of the links was based on observations of curve shape variations together with peak values found from tabulated 
data. Finally, a tentative curve fit to describe the changes in the number of complaints was tested based on learning curve. The data also contain summarized numerical information about items and complaints but the focus is on welding supplier information.

The studied data comprise information about the number of individual items, where the total number of items in the end product is not given. The category total number of items includes also the number of the same items (Table 1). Complaints are observed similarly at a general level and also focusing on items manufactured by welding suppliers. In this analysis, welding supplier items are outsourced parts manufactured by a supplier who does welding manufacturing of parts or subassemblies for the focal company. Complaints values show the number of individual complaints and do not take into account the number of items within a single complaint. Either observing costs are only indicated items, not manufacturing activities. The welding supplier data were divided into different categories for analysis with a mixed method approach [30] with numerical data and clarification results according to the root cause of the complaints.

Table 1. Data calculation example of number of individual items and total number of items. The number of individual items describes every new item number in the end product.

\begin{tabular}{lll}
\hline Item number & Item description & Quantity \\
\hline 34966 & Fastener & 12 \\
42815 & Cover sheet & 6 \\
43467 & Shaft & 2 \\
21201 & Sleeve & 4 \\
Number of individual items & & 4 \\
Total number of items & & 24 \\
\hline
\end{tabular}

* The data are collected from an item group of 3891 individual items where the total number of items is 14907.

The machines studied illustrate the number and cause of complaints in the end product. The complaints data used are general information about complaints regarding items in production and, in this work, are not assigned to particular machines. However, the data show the connection between welded items and the volume of complaints and thus indicate prospects of improving production profitability. Complaints can be observed with general categorization of all complaints in a welding network whereas this study focuses on studying complaints from the viewpoint of an example end product.

\subsection{Finding Connections Between the Content of Complaints and the Items of the End Product}

This research concentrates on three main areas. One focus is summarization of numerical information about items and complaints concerning two example end products (Machine A and Machine B) over an eight year period. This part also shows information about complaints in the launching year of the product. The second focus is study of costs related to items that have been the subject of complaints and analysis of the correlation of these costs to the end product. The third focal point is categorization of complaints on the basis of root cause.
The number of complaints relative to the number of items for Machine A and Machine B is presented in Table 2. The table includes the percentage share of items manufactured by welding suppliers and the total number of items, and also the number of complaints relative to the number of items manufactured by the welding suppliers. The share of items related to welding suppliers relative to the number of items about which complaints are received is considerable, thus the impact of welding suppliers on the end product is evident. As explained earlier, these results are the share of complaints linked to an individual item and as the end products may include several of the same items, the value does not take into consideration the total number of items or complaints. Therefore, Table 3 shows the share of the total number of items manufactured by the welding suppliers. The total number of items in Machine A is 4.06 times and in Machine B 3.74 times the number of individual items. The total number of complaints, including complaints not related to the welding suppliers, was for Machine A 1.38 times and for Machine B 0.65 times the total number of complaints about individual items. From Table 2 and Table 3 it can be seen that the share of individual items related to welding suppliers has reduced by $13 \%$ - $15 \%$ but the complaints to welding suppliers is still prominent when the difference in composition of the items, e.g. multipart welded structures and bulk items, is taken into consideration.

Table 2. The share of number of complaints, items related to welding supplier and complaints related to welding supplier for Machine $A$ and Machine B.

\begin{tabular}{|c|c|c|c|}
\hline Description & Machine A & Machine B & Average \\
\hline $\begin{array}{l}\text { Number of complaints / } \\
\text { Number of individual items }\end{array}$ & $24.18 \%$ & $14.65 \%$ & $19.42 \%$ \\
\hline $\begin{array}{l}\text { Items related to welding } \\
\text { suppliers / Number of } \\
\text { individual items }\end{array}$ & $22.55 \%$ & $27.73 \%$ & $25.14 \%$ \\
\hline $\begin{array}{l}\text { Complaints of items related to } \\
\text { welding suppliers / Number of } \\
\text { complaints }\end{array}$ & $29.70 \%$ & $37.65 \%$ & $33.68 \%$ \\
\hline
\end{tabular}

* The data are collected from an item group of 3891 individual items where the total number of items is 14907 .

Table 3. Total number of items manufactured by welding suppliers and complaints related to welding suppliers for the case end product.

\begin{tabular}{llll}
\hline Description & Machine A & Machine B & Average \\
\hline $\begin{array}{l}\text { Total number of items related } \\
\text { to welding suppliers / Total } \\
\text { number of items }\end{array}$ & $8.74 \%$ & $10.74 \%$ & $9.74 \%$ \\
$\begin{array}{l}\text { Total number of complaints } \\
\text { related to welding supplier / } \\
\text { Total number of complaints }\end{array}$ & $21.62 \%$ & $19.29 \%$ & $20.45 \%$ \\
\hline
\end{tabular}

* The data are collected from an item group of 3891 individual items where the total number of items is 14907.

Total complaints in the year of launch of the machines, 2008 , the number of complaints related to welding suppliers was $24 \%$ and in $201425 \%$. The total number of complaints was 4.68-fold (for Machine A) and 2.05-fold (for Machine B) the number of complaints about individual items. However, 
the number of complaints in the year of launch related to case products is presented in Table 4. The difference in the results for Machine A and Machine B can be explained by the totally new design and assembly of Machine B and therefore the sensitivity of the welded items to complaints.

Cost of items of particular end products are counted using information about the total number of related items. The complete end products contain some very expensive items as welded items, e.g. motor and power transmission. Excluding the three most expensive items, the total cost of items manufactured by welding suppliers raises, and by excluding the five most expensive items, the amount continues to grow. Table 5 shows the relative cost of items about which complaints have been received by welding suppliers for all parts and when the most expensive items are excluded.

Table 4. Launching year information of complaints of items related to welding supplier and total quantity of welding supplier complaints.

\begin{tabular}{|c|c|c|c|}
\hline Description & Machine A & Machine B & Average \\
\hline $\begin{array}{l}\text { Number of individual } \\
\text { complaints related to welding } \\
\text { suppliers in launching year } \\
\text { Total number of complaints } \\
\text { related to welding suppliers in } \\
\text { launching year }\end{array}$ & $14.29 \%$ & $37.02 \%$ & $25.65 \%$ \\
\hline
\end{tabular}

Table 5. Relative cost of items in the case end products for all items and without the most expensive items.

\begin{tabular}{|c|c|c|c|}
\hline Description & Machine A & Machine B & Average \\
\hline $\begin{array}{l}\text { Cost of items related to } \\
\text { welding suppliers }\end{array}$ & $9.93 \%$ & $13.28 \%$ & $11.61 \%$ \\
\hline $\begin{array}{l}\text { Without } 3 \text { the most expensive } \\
\text { items }\end{array}$ & $29.31 \%$ & $26.91 \%$ & $28.11 \%$ \\
\hline $\begin{array}{l}\text { Without } 5 \text { the most expensive } \\
\text { items }\end{array}$ & $33.38 \%$ & $28.21 \%$ & $30.80 \%$ \\
\hline $\begin{array}{l}\text { Cost of complained items } \\
\text { related to welding suppliers }\end{array}$ & $6,35 \%$ & $5,08 \%$ & $5,72 \%$ \\
\hline $\begin{array}{l}\text { Without } 3 \text { the most expensive } \\
\text { items }\end{array}$ & $18,74 \%$ & $10,30 \%$ & $14,52 \%$ \\
\hline $\begin{array}{l}\text { Without } 5 \text { the most expensive } \\
\text { items }\end{array}$ & $21,35 \%$ & $10,79 \%$ & $16,07 \%$ \\
\hline
\end{tabular}

* The data are collected from an item group of 3891 individual items where the total number of items is 14907 .

The ratio of the number of complaints related to the number of items in the end products manufactured by welding suppliers to all complaints to the welding suppliers divided in years is given in Fig. 1. General market conditions and investment in product development is reflected in the number of complaints in a particular year. Machine A has been under development for several years with revision of many items, which affects the rate of complaints. Machine B is a totally new design structure and the number of complaints first rises continuously before settling down. One approach to interpretation of the curves in Fig. 1 is utilization of learning curve theories. The learning process is complex [31] and learning rate is not constant [32]. It can be expected that quality is lower and costs are higher when there is a lack of learning [32]. Consequently, after initial launch of a product, the trend of complaints is a rising curve that peaks before starting to decrease. The continuous line in Fig. 1 describes production of Machine A, where the number of welding errors increases to a peak in 2012 before falling due to the effect of organizational learning. Assuming that organizational learning for Machine B follows a similar pattern, the dashed line can be expected to peak after a few years and then decline. The welding error lines resemble each other but learning is at different stages of the learning life cycle with different intensity of development. Curve behaviour depends on how much development and how many revisions are made and therefore the number of complaints will probably never drop to zero.

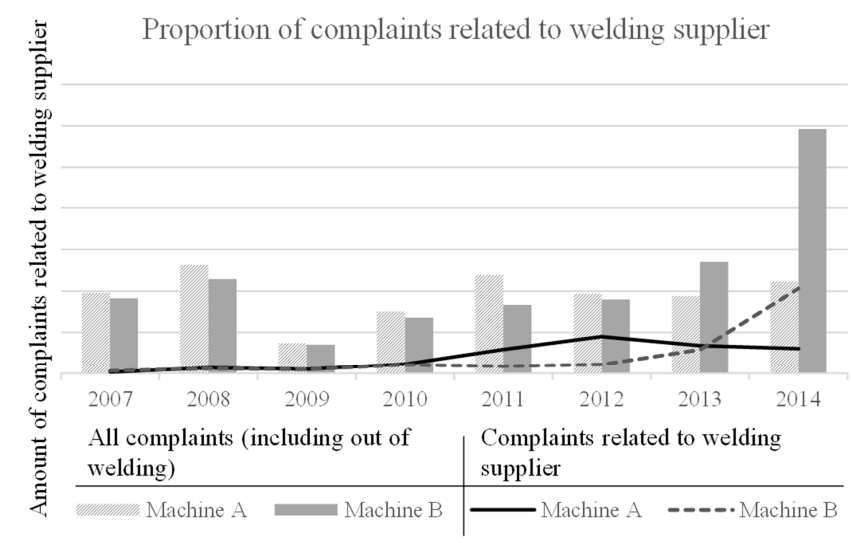

Figure 1. Complaints related to welding suppliers in the studied machines for 2007-2014. From the two curves it can be concluded that the trend of complaints is rising and presumably after reaching a peak it will start to decrease.

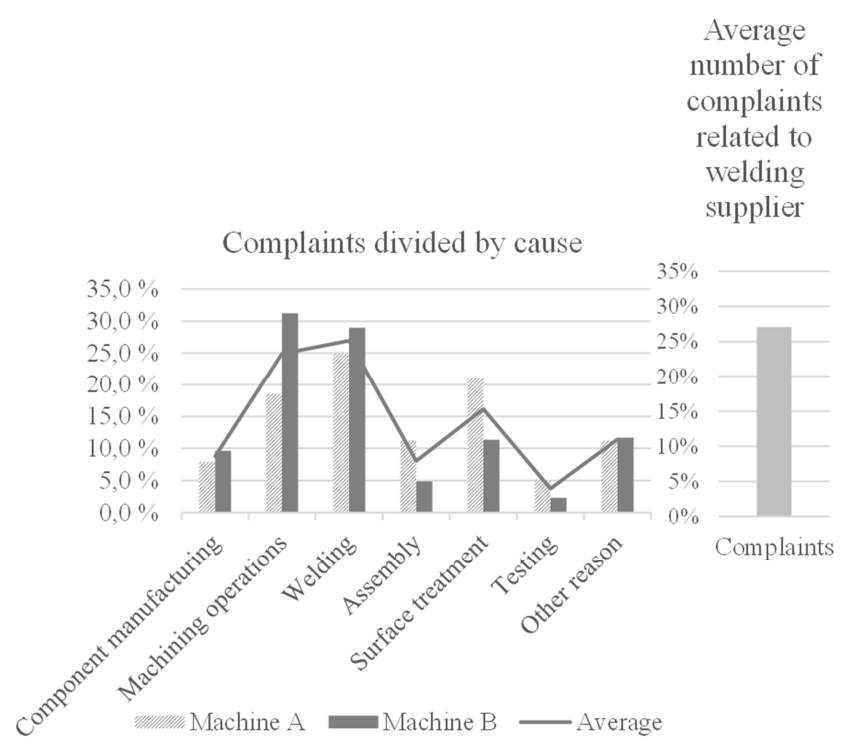

Figure 2. Proportion of complaints related to welding supplier in particular machines divided by root cause phases in welding manufacturing in years 2007-2014. From the diagram it can be concluded that welding-related functions are important factors in welding manufacturing.

The data in Fig. 1 do not relate to a specific reason or cause of complaint. However, to improve manufacturing productivity and decrease the number of defects, it is 
important to establish the underlying cause of complaints. Complaints for 2007-2014 related to welding suppliers are categorized by root cause and phase in welding manufacturing in Fig. 2. Welding includes supporting activities and actual welding is only one part of the welding functions needed to reach the quality requirements of the manufactured product. In Fig. 2, welding activities are divided by actions related to welding activity. The figure also shows the average proportional share of the average number of complaints related to welding suppliers when the number of the items and total quantity of items are included.

\section{Discussion}

Defects are common in production [10] and despite existing models of quality costs [7] companies are still required to deal with defective manufacturing. Liu et al. [26] states that the manufacturer is responsible for product quality and price, and this responsibility drives companies to make efforts to ensure conformity of manufacturing throughout the supply chain. Complaints are non-compliant actions in manufacturing and inevitably cause extra costs. Reducing such non-lucrative activity might increase production profitability. The achievable gain depends on the efforts required to reduce the number of complaints by investing in quality actions and improvements in different functions of the production chain.

In the study, the end products are two different machines constructed of multiple items and designed for equivalent end use. Approximately $25 \%$ of the individual items are manufactured by welding suppliers, which forms approximately $10 \%$ of the total number of items utilized in production. This correlates with the notable role of welding in manufacturing because the number of welded parts relative to all items is disproportionate. Welded items usually entail bigger workload and the required number of pieces is smaller than ancillary items like bulk items, which have all individual item number. The coefficient of the number of items relative to the individual number of items confirms this finding.

Observing the complaints more closely, individual items manufactured by the welding supplier (Machine A and Machine B) caused $34 \%$ of the total complaints about individual items. Over the period studied, complaints made to welding suppliers show that the mean amount of complaints dealing with Machine A and Machine B is about the same as in the whole welding production (Fig. 3). The number of complaints varies depending on production volume but the rate is visible. In Fig. 3, the launching year position of welding supplier complaints can be seen. Even though the complaints are not related to particular machines and show the number of marked complaints and do not take into account the number of items inside a single complaint, the results gives an overview of the significance of complaints in welding production.

Cost of items of end products is not contained in manufacturing costs and therefore is not relevant for observing the total cost of the end product. However, the cost of items indicate the material investment and therefore have a big impact on total costs. As noted earlier, the end products contain multiple items and different items will involve different workload. The cost of items manufactured by welding suppliers is approx. $12 \%$ of total cost of items of product. Excluding the five most expensive items, the figure is 2.7-fold compared previous and excluding only the three most expensive items, the figure is still 2.4 -fold. This shows that welding suppliers are responsible for a third of the manufacturing potential of the end product, and therefore managing supplier quality occupies a very important position in the manufacturing operations. The cost of items manufactured by welding suppliers about which complaints are received follows the same rate as total items manufactured by welding supplier with 2.8 -fold (excluding five items) and 2.5-fold (excluding three items) results compared to without excluding any of items. Excluding the five most expensive items gives the result of $16 \%$ of total items that welding suppliers are responsible for.

The total number of complaints to the welding suppliers varies over the eight years period. It is difficult to analyse any regular trend by items of particular end product of these years. Although, these case end products seem to be close to general trend of all complaints. The launching year of the end product and the general market situation also have an impact on production. Categorizing the complaints of case machines by root cause of manufacturing phase indicates the importance of welding-related functions. Actual welding is near third of reason for complaints related to welding suppliers.

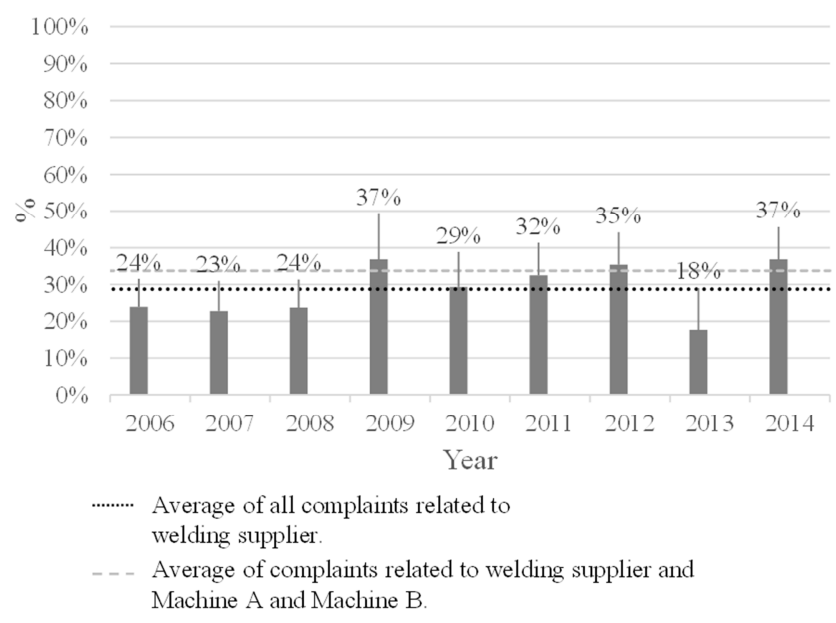

Figure 3. The number of complaints related to welding suppliers seems to remain relatively stable year-on-year.

\section{Conclusion}

Pettersson and Segerstedt [33] state that manufacturing costs are only one part of supply chain costs. This study shows the potential of welding production functions to increase production profitability by reducing manufacturing defects that cause complaints. In the light of the results presented, the effect of complaints on quality and costs is evident. The results also indicate the potential to influence 
the quality and profitability of the end product by control of complaints in the supplier chain. This shows the prospect to impact disadvantages on welding production.

This research observed complaints and costs from the viewpoint of items, in future research it would be interesting to focus on costs of manufacturing through complained items and therefore their impact on total costs of the end product. Such information is essential when making efforts to improve manufacturing quality and profitability from whole welding network viewpoint. This research shows one approach to study of the effect of manufacturing in the supply chain on end product. Other studies could concentrate on categorization of complaints in a welding supplier network by root cause and finding the link between complaints, knowledge transfer and competencies. Additionally, the effect of complaints on revisions of welded items in a welding supplier network would be interesting to define. Wider observation is needed in the state of network pictures of welding network and influence on the amount of complaints in welding production.

\section{References}

[1] S. T. Foster Jr. and J. Ogden. On differences in how operations and supply chain managers approach quality management, International Journal of Production Research, Vol 46 (24), 2008, pp. 6945-6961. doi: 10.1080/00207540802010815.

[2] S. T. Foster Jr., S. T., C. Wallin and J. Ogden. Towards a better understanding of supply chain quality management practices, International Journal of Production Research, Vol 49 (8), 2011, pp. 2285-2300. doi: 10.1080/00207541003733791.

[3] R. Schmitt and A. Linder. Technical complaint management as a lever for product and process improvement, CIRP Annals Manufacturing Technology, Vol. 62 (1), 2013, pp. 435-438. doi: 10.1016/j.cirp.2013.03.040.

[4] M. Srinivasan, D. Mukherjee and A. S. Gaur. Buyer-supplier partnership quality and supply chain performance: Moderating role of risks, and environmental uncertainty, European Management Journal, Vol. 29 (4), 2011, pp. 260-271. doi: 10.1016/j.emj.2011.02.004.

[5] L. J. Zeballos, M. I. Gomes, A. P. Barbosa-Povoa and A. Q. Novais. Addressing the uncertain quality and quantity of returns in closed-loop supply chains, Computers and Chemical Engineering, Vol. 47, 2012, pp. 237-247. doi: 10.1016/j.compchemeng.2012.06.034.

[6] G. Xie, W. Yue, S. Wang and K. K. Lai, Quality investment and price decision in a risk-averse supply chain, European Journal of Operational Research, vol. 214, 2011, pp. 403-410. doi: 10.1016/j.ejor.2011.04.036.

[7] K. K. Castillo-Villar, N. R. Smith and J. L. Simonton, The impact of the cost of quality on serial supply - chain network design, International Journal of Production Research, vol. 50, 2012, pp. 5544-5566. doi: 10.1080/00207543.2011.649802.

[8] W. Wang, R. D. Plante and J. Tang, Minimum cost allocation of quality improvement targets under sup-plier process disruption, European Journal of Operational Research, vol 228, 2013, pp. 388-396. doi: 10.1016/j.ejor.2013.01.048.

[9] B. Ivens and C. Pardo, Are key account relationships different? Empirical results on supplier strategies and customer reactions, Industrial Marketing Management, vol. 36 (4), 2007, pp. 470-482. doi: 10.1016/j.indmarman.2005.12.007.

[10] R. Xiao, Z. Cai and X. Zhang, A Production Optimization Model of Supply-driven Chain with Quality Uncertainty, Journal of Systems Science and Systems Engineering, vol. 21 (2), 2012, pp. 144-160. doi: 10.1007/s11518-011-5184-8.

[11] T. Garín-Muñoz, T. Pérez-Amaral, C. Gijón and R. López, Consumer complaint behavior in telecommunications: The case of mobile phone users in Spain, Telecommunications Policy, 2015. doi: 10.1016/j.telpol.2015.05.002i.

[12] P-W Dong and Y-Q Huang, Research of Customer Complaints and Service Recovery Effects, Management Science and Engineering, 2006, pp. 958-962, October 2006 [ICMSE '06 International Conference, Lille]. doi: 10.1109/ICMSE.2006.314008.

[13] M. A. Lapré, Reducing Customer Dissatisfaction: How Important is Learning to Reduce Service Failure?, Production and Operations Management, vol. 20 (4), 2011, pp. 491-507. doi: $10.1111 / J .1937-5956.2010 .01149$.

[14] A. Yim, Failure Risk and Quality Cost Management in Single versus Multiple Sourcing Decision, Decision Sciences, vol. 45 (2), 2014, pp. 341-354. doi: 10.1111/deci.12070.

[15] X. Huang, S-M. Choi, W-K. Ching, T-K. Siu and M. Huang, On supply chain coordination for false failure returns: A quantity discount contract approach, International Journal of Production Economics, vol. 133 (2), 2011, pp. 634-644. doi: 10.1016/j.ijpe.2011.04.031.

[16] S. Sharma, Effects concerning quality level with the increase in production rate, International Journal of Advanced Manufacturing Technology, vol. 53 (5-8), 2011, pp. 629-634. doi: 10.1007/s00170-010-2851-8.

[17] R. Mateo, M. Tanco and J. Santos, Less Expert Workers and Customer Complaints: Automotive Case Study, Human Factors and Ergonomics in Manufacturing \& Service Industries, vol. 24 (4), 2014, pp. 444-453. doi: 10.1002/hfm.20396.

[18] B. Gajdzik, B. and J. Sitko, An analysis of the causes of complaints about steel sheets in metallurgical product quality management systems, Metallurgia, vol. 53 (1), 2014, pp. $135-138$.

[19] B. C. Giri and S. Sharma. Optimizing a closed-loop supply chain with manufacturing defects and quality dependent return rate, Journal of Manufacturing Systems, vol. 35, 2015, pp. 92111. doi: 10.1016/j.jmsy.2014.11.014.

[20] T. Gruber, S. C. Henneberg, B. Ashnai and P. Naudé, Complaint resolution management expectations in an asymmetric business-to-business context, Journal of Business \& Industrial Marketing, vol. 25 (5), 2010, pp. 360-371. doi: $10.1108 / 08858621011058124$

[21] G. A. Akyuz and T. E. Erkan, Supply chain performance measurement: a literature review, International Journal of Production Research, vol. 48 (17), 2010, pp. 5137-5155. doi: 10.1080/00207540903089536.

[22] N. Panayiotou and K. G, Aravosis, Supply Chain Management, in Theory and Practice of Corporate Social Responsibility, S. O. Idowu and C. Louche, Eds. Berlin Heidelberg: Springer-Verlag, 2011, pp. 55-70. doi: 10.1007/978-3-642-16461-3_4. 
[23] B. Nepal and O. P. Yadav, Bayesian belief network-based framework for sourcing risk analysis during supplier selection, International Journal of Production Research, vol. 53 (20), 2015, pp. 6114-6135. doi: 10.1080/00207543.2015.1027011.

[24] J. Toivanen, J. Martikainen and P. Heilmann, From supply chain to welding network: A framework of the prospects of networks in welding, Mechanika, vol. 21 (2), 2015, pp. 154160. doi: 10.5755/j01.mech.21.2.8463.

[25] J. Toivanen, P. Kah and J. Martikainen, Quality Requirements and Conformity of Welded Products in the Manufacturing Chain in Welding Network, International Journal of Mechanical Engineering and Applications, vol. 3 (6), 2015, pp. 109-119. doi: 10.11648/j.ijmea.20150306.12.

[26] G. Liu, S. P. Sethi and J. Zhang, Myopic vs. far-sighted behaviours in a revenue-sharing supply chain with reference quality effects, International Journal of Production Research, 2015, doi: 10.1080/00207543.2015.1068962.

[27] C. Hicks, O. Heidrich, T. McGovern and T. Donnelly, A functional model of supply chains and waste, International Journal of Production Economics, vol. 89 (2), 2004, pp. 165174. doi: 10.1016/S0925-5273(03)00045-8.

[28] M. Firoozi, A. Siadat, N. Salehi and S. M. Mousavi, A Novel
Multi-Objective Fuzzy Mathematical Model for Designing a Sustainable Supply Chain Network Considering Outsourcing Risk under Uncertainty, Industrial Engineering and Engineering Management, 2013, pp. 88-92, December 2013 [IEEE International Conference, Bangkok] doi: 10.1109/IEEM.2013.6962380.

[29] X. Tang, X. and H. Yun, Data model for quality in product lifecycle, Computers in industry, vol. 59 (2-3), 2008, pp. 167179. doi: 10.1016/j.compind.2007.06.011.

[30] G. Guest, E. E. Namey and M. L. Mitchell, Collecting Qualitative Data: A Field Manual for Applied Research. Thousand Oaks: Sage Publications Inc., 2013, pp. 16-17.

[31] P. S. Adler and K. B. Clark, Behind the learning curve: A sketch of the learning process, Management Science, vol. 37 (3), 1991, pp. 267-281.

[32] M. A. Lapré, A. S. Mukherjee and L. N. Van Wassenhove, Behind the Learning Curve: Linking Learning Activities to Waste Reduction, Management Science, vol. 46 (5), 2000, pp. 597-611. doi: 10.1287/mnsc.46.5.597.12049.

[33] A. Pettersson and A. Segerstedt, Measuring supply chain cost, International Journal of Production Economics, vol. 143 (2), 2013, pp. 357-363. doi: 10.1016/j.ijpe.2012.03.012. 